Short Communication

\title{
Study on Preparation and Performance of PEO-PVDF Composite Binder for Lithium ion Batteries
}

\author{
Xinghua Liang ${ }^{1,2,{ }^{*}}, \mathrm{Xi} \mathrm{Wu}^{1}$, Yunting Wang ${ }^{1}$, Xinqi $\mathrm{Li}^{1}$, Qixin Gai ${ }^{1}$, Jie Mao ${ }^{2}$ \\ ${ }^{1}$ Guangxi Key Laboratory of Automobile Components and Vehicle Technology, Guangxi University \\ of Science \& Technology, Liuzhou 545006, China; \\ ${ }^{2}$ National Engineering Laboratory for Modern Materials Surface Engineering Technology, \\ Guangdong Institute of New Materials, Guangdong Academy of Science, Guangzhou 510650, China. \\ *E-mail: 1xh304@aliyun.com (Xinghua Liang)
}

doi: $10.20964 / 2020.09 .79$

Received: 13 May 2020 / Accepted: 2 July 2020 / Published: 10 August 2020

PEO-PVDF composite binder was used to prepare lithium manganate positive pole piece and its phase and morphology were characterized by X-ray diffractometer (XRD) and scanning electron microscope (SEM). At the same time, CV, AC resistance and charge-discharge tests are used to perform electrochemical performance tests. The results appearanced that the specific discharge capacity of the battery declined from $113 \mathrm{mAh} / \mathrm{g}$ to $88 \mathrm{mAh} / \mathrm{g}$ after 150 cycles, and the Coulomb efficiency remains at about $99 \%$. And the CV curve almost coincides with 100 times, which indicates excellent cycle performance.

Keywords: $\mathrm{LiMn}_{2} \mathrm{O}_{4}$; Lithium ion battery; Binder; PEO-PVDF; Cycle performance

\section{FULL TEXT}

(C) 2020 The Authors. Published by ESG (www.electrochemsci.org). This article is an open access article distributed under the terms and conditions of the Creative Commons Attribution license (http://creativecommons.org/licenses/by/4.0/). 